majority were engineering students. Some indication of the exceptional range and standard of the evening classes is given by the fact that the enrolment included 100 graduates of universities of Scotland, England, Ireland, Canada, India and China. An important, and seemingly long overdue event of the year was the formation of a Former Students' Association with a membership of seven hundred and correspondents in many parts of the world. The Association aims at "enabling former students to retain an interest in the affairs of the College" and as the honorary secretary is a member of the staff it may be hoped that it will help the College to retain an interest in the former students. An important source of strength for the College is the scheme of affiliation of continuation classes conducted by eight county education authorities and attended by more than seven thousand students. The Glasgow Careers Council (for Secondary Schools) co-operates with the Ministry of Labour in promoting visits of boys and girls with their teachers to various departments of the College.

\section{University Studies at Jerusalem}

A BULLETIN recently issued by the Hebrew University at Jerusalem discloses the fact that Polish students largely outnumber all others. The total enrolment last year was 779 , including 48 research students. Of the undergraduates, 433 were from Poland, 150 from Palestine, 49 from Germany, 35 from Lithuania and Latvia, 17 from Rumania and the rest from 18 other countries. The same bulletin contains an article by Dr. Dushkin, lecturer in educational method and administration, on the various activities of his department, including measures for improving and extending the teaching of Arabic. In the Palestinian schools, Arabic has been taught like Latin or Greek, with stress upon the analysis of grammatical forms and translation of classic texts. The University's policy is, on the contrary, to emphasize the conversational aspects of the language and to promote the employment of a minimum course for all Jewish children in colloquial Arabic, with simple reading and writing and instruction in Arabic folk.ways and customs. This is a diff. cult task owing to the prevalence of a snobbish contempt for the 'vulgar' spoken language of the common people, which differs widely from the classic Arabic of literature and is not taught by the Arabs in their own schools. The department is largely under the influence of American educational theory, the chair of the principles of education being held by Prof. Kaplan of New York, for many years a professor at the Jewish Theological Seminary there and principal of its Teachers' Institute, and a leader of the Society for the Advancement of Judaism and of the Reconstruction Movement in American Jewry.

\section{King Edward's Hospital Fund for London}

THE fortieth annual report of King Edward's Hospital Fund for London, recently issued and covering the year 1936, gives an account of the finances of the Fund and of the grants recommended. The ordinary distribution remained unchanged at
$£ 300,000$, to which was added a first contribution of $£ 2,000$ in respect of work done for hospital outpatients by district nursing associations. Grants were made to 146 hospitals and 56 convalescent homes. The contributions to the Fund included a capital gift of $£ 20,000$ from His late Majesty, King George V. The Fund has acquired an additional 7 grams of radium, thus bringing the amount under the Fund's control up to a total of 17 grams. An account is given of the work of the Propaganda Committee, which includes the production of a new film on hospital progress, specially suited to school audiences.

\section{Eradication of Bovine Tuberculosis}

THE Register of Attested Herds in Great Britain, under the Tuberculosis (Attested Herds) Schemes, which has been recently published, gives particulars of the herds on the Register on December 31. At that date there were 812 attested herds with 37,000 cattle in England and Wales, and 640 herds in Scot. land with 50,500 cattle, a considerable increase over the previous year. The Register gives the names and addresses of the owners and the breeds of cattle, and can be obtained on application to the Ministry of Agriculture and Fisheries, 7 Whitehall Place, London, S.W.1, or, for Scotland, 15 Moray Place, Edinburgh, 3. The issue of a certificate of attestation is evidence that the owner of the herd has taken steps to eradicate tuberculosis from the herd, and that as a result of an official tuberculin test, the herd has been found to be free from tuberculosis.

\section{Air-borne Traffic and Infectious Diseases}

The Minister of Health has made regulations, similar to the Port Sanitary Regulations, 1933, designed to prevent the introduction of infectious diseases into Great Britain through the medium of air-borne traffic which came into force on July 1. The authorities responsible for the administration of these "Aircraft Regulations" are the port health authorities for aerodromes at ports, and elsewhere the local authorities of the districts in which the aerodromes are situated. The regulations authorize, if necessary, temporary detention of aircraft, medical inspection of passengers and crews, cleansing, disinfection, etc. The issue of these regulations marks a further advance in the policy for the provision of health services suitable for modern conditions.

\section{The Vale of Neath}

THE National Museum of Wales has initiated a series of studies of the origin of Welsh scenery with a small pamphlet on the "River Scenery at the Head of the Vale of Neath", by Dr. F. J. North. The area covered is about sixty square miles and is one of great scenic charm. The studies do not necessarily embody original work, but they aim at giving popular descriptions of the origin of the land forms with as little use of technical terms as possible. Where technicalities are unavoidable they are fully explained. The present study is a good example of intelligent popularization both in its wording and its diagrams and illustrations. 